\title{
Ovalbumin-induced plasma interleukin-4 levels are reduced in ceramide kinase-deficient DO11.10 $\mathrm{RAG1}^{-1-}$ mice
}

\author{
Satoru Niwa' ${ }^{1}$, Nicole Urtz ${ }^{1,2}$, Thomas Baumruker ${ }^{1}$, Andreas Billich, Frédéric Bornancin ${ }^{1 *}$
}

\begin{abstract}
Ceramide kinase (CERK) produces the bioactive lipid ceramide-1-phosphate (C1P) and is a key regulator of ceramide and dihydroceramide levels. It is likely that CERK and C1P play a role in inflammatory processes but the cells involved and the mechanisms used remain to be clarified. In particular, the impact of CERK on T-cell biology has not been studied so far. Here, we used Cerk ${ }^{-1-}$ mice backcrossed with DO11.10/RAG ${ }^{-1-}$ mice to probe the effect of CERK ablation on T-cell activation. Levels of interleukin (IL)-2, IL-4, IL-5, IL-13, of tumor necrosis factor (TNF)- $\alpha$, and of interferon (INF)- $\gamma$ were recorded following ovalbumin challenge in vivo and using ovalbumin-treated splenocytes ex- vivo. Absence of CERK led to a significant decrease in the production of IL-4, thus suggesting that CERK may polarize $T$ cells towards the $T_{H} 2$ cell subtype. However, the importance of CERK to $T_{H} 2$ cell biology will have to be investigated further because in a model of asthma, which is $T_{H} 2$-cell driven, Cerk ${ }^{-1-}$ mice responded like wild-type animals.
\end{abstract}

\section{Background}

Ceramide kinase (CERK), together with sphingosine kinases (SPHK) 1 and 2, belongs to the diacyglycerol kinase family of lipid kinases. CERK is the only enzyme known to produce ceramide-1-phosphate (C1P) [1]. However, studies with CERK deficient $\left(\mathrm{Cerk}^{-1-}\right)$ mice have shown that another route for production of C1P must exist, at least in mammals [2,3]. The best described signaling properties reported for C1P include, on the one hand, a positive effect on cell proliferation and cell survival $[4,5]$ and, on the other hand, the control of cytosolic phospholipase A2 (cPLA2) activity [6-9]. Of note, however, neither knocking down the Cerk gene [3] nor using a CERK inhibitor [10] could recapitulate these findings, which suggests compensation by other C1P pools that do not depend on CERK for their synthesis.

The physiological role of CERK and its relevance to disease is only starting to be addressed. Using a gene knockdown strategy Igarashi and coworkers have shown preliminary evidence for a role of CERK in emotional

\footnotetext{
* Correspondence: frederic.bornancin@novartis.com

${ }^{1}$ Novartis Institutes for BioMedical Research, Brunnerstrasse 59, A-1235
} Vienna, Austria

(c) 2010 Niwa et al; licensee BioMed Central Ltd. This is an Open Access article distributed under the terms of the Creative Commons Attribution License (http://creativecommons.org/licenses/by/2.0), which permits unrestricted use, distribution, and reproduction in any medium, provided the original work is properly cited. behavior [11]. Based on ex- vivo work with CERK-deficient endothelial cells together with use of the CERK inhibitor NVP-231 [10] our laboratory has recently proposed a role for CERK in the regulation of angiogenesis [12]. CERK may also be relevant to immune cell biology. In fact, neutrophils represent one of the first cell types where CERK/C1P were described [13-15] and subsequently shown to promote phagolysosome formation [16]. More recently, the study of C1P/CERK in mast cells has suggested their function in the degranulation process [17]. Consistently, in a model of passive cutaneous anaphylaxis, $\mathrm{Cerk}^{-1-}$ animals were partially protected [3]. However, $\mathrm{Cerk}^{-1-}$ responded similarly to control littermates during a model of active cutaneous anaphylaxis [3]. In fact, work in vitro with CERK-deficient primary bone marrow derived mast cells or with the NVP-231 inhibitor failed to clarify a putative role of CERK/C1P in mast cell biology [3,10]. In an antigeninduced arthritis model, Cerk $^{-1-}$ mice were not protected, thus inconsistent with the hypothesis that C1P made by CERK is key for cPLA2 activation in vivo - parallel pharmacological inhibition of cPLA2 could indeed dampen disease development [3]. In sharp contrast, absence of CERK prevented $\mathrm{Cerk}^{-1-}$ animals from mounting an effective response against a pulmonary insult by 
Streptococcus pneumoniae [3]. Altogether, although CERK seems to play a role in inflammation, the overall picture remains contrasted and no consensus has emerged yet.

The study reported here was undertaken to examine $\mathrm{T}$-cell specific responses in the absence of CERK. To this aim we made use of the established DO11.10 $\mathrm{RAG1}^{-/-}$background [18-20]. In DO11.10 mice all thymocytes and peripheral $\mathrm{T}$ cells express the transgenic TCR receptor from a $\mathrm{T}$ cell hybridoma, DO11.10, that recognizes chicken ovalbumin (OVA) in the context of I- $\mathrm{A}^{\mathrm{d}}$ class II MHC molecules. Furthermore, in DO11.10/ $\mathrm{RAG}^{-/-}$mice, the endogenous TCR $\alpha$-chains are eliminated, and $\mathrm{T}$ cells can only express the transgenic receptor. This model has proven useful for studying $\mathrm{T}$-cell specific responses. Therefore, we backcrossed $\mathrm{Cerk}^{-1-}$ mice with DO11.10/RAG1 ${ }^{-/}$mice to probe the effect of CERK ablation on T-cell activation. In parallel, we also backcrossed $S p h k 1^{-/-}$and $S p h k 2^{-/-}$to the same background for comparison.

\section{Methods}

\section{Generation of D011.10 RAG $1^{-/-}$mice strains}

Mice deficient in either CERK, SPHK1 or SPHK2 were backcrossed with DO11.10 $\mathrm{RAG}^{-/-}$mice; all strains were on a Balb/C background. Deficiency for CERK, SPHK1 or SPHK2 was analyzed by RT-PCR as previously described [3,21]. For examination of the expression of the transgenic TCR receptor, blood was taken from the retro-bulbar complex, erythrocytes were lysed and T cells were stained with an anti KJ 126- FITC conjugated antibody (Caltag) and analyzed by flow cytometry (Becton Dickinson Excalibur).

\section{Ovalbumin challenge in vivo}

On day 0 and 5 , mice were sensitized by intraperitoneal injections of alum-precipitated ovalbumin (OVA) containing $100 \mu \mathrm{g}$ OVA (Sigma) absorbed to $2 \mathrm{mg} \mathrm{Al}(\mathrm{OH})_{3}$ (Alu Gel S $\left(2 \% \mathrm{Al}(\mathrm{OH})_{3}\right.$, Serva) and diluted with saline to a volume of $0.2 \mathrm{ml}$.

\section{Splenocyte isolation, culture and ovalbumin treatment}

After immunization with OVA as described above, spleens were isolated and single splenocyte suspensions were prepared by lysing erythrocytes with FACS Lysing Solution (Becton Dickinson). One million cells/well of splenocytes were seeded in 96 well plates (Becton Dickinson), and incubated with $10 \mu \mathrm{g} / \mathrm{ml} \mathrm{OVA}_{323-339}$ peptide for 3.5 hours in RPMI1640 supplemented with $100 \mathrm{U} /$ $\mathrm{ml}$ penicillin, $100 \mu \mathrm{g} / \mathrm{ml}$ streptomycin sulfate and $10 \%$ FBS. After the incubation, culture supernatant were harvested, and kept at $-20^{\circ} \mathrm{C}$ until cytokine measurement.

\section{Cytokine measurements}

For parallel determination of cytokines in serum multiplex reagents from BioRad were used; analyses were conducted using a BioPlex 200 System, the BioPlex Pro reagent kit and human standards group I + II. Cytokine concentrations in the samples were calculated from calibration curves using the software XL-fit (IDBS Ltd.). IL4 levels in culture medium of isolated splenocytes were measured by enzyme-linked immunosorbent assay (ELISA), following the manufacturer's instructions (R\&D Systems).

\section{Asthma model}

On days 0 and 5, mice were sensitized by intraperitoneal injection of alum-precipitated ovalbumin (cf above) and diluted with saline to a volume of $0.2 \mathrm{ml}$. On day 0 and $13,200 \mu \mathrm{l}$ blood was collected by puncture of the retrobulbar plexus under isoflurane anesthesia. Sera were prepared and stored frozen at $-20^{\circ} \mathrm{C}$ until analyzed for OVA-specific IgE and IgG1in serum. On day 12, the animals were challenged with aerosolized OVA $(1.0 \%$ wt/vol in PBS) for 60 min, twice. The aerosol was generated by a "Small Particle Aerosol Generator" (SPAG-2, Serotherapeutisches Institut) driven by compressed air at $6 \mathrm{l} / \mathrm{min}$. Under these conditions the median particle diameter was $0.5 \mu \mathrm{m}$. Forty eight hours after the first aerosol exposure, mice were euthanized with pentobarbital (Nembutal $70 \mu \mathrm{l} /$ mouse i.p.). The trachea was trimmed free of connective tissue and a cannula was inserted. The lungs were lavaged with $3 \times 1 \mathrm{ml}$ saline at $37^{\circ} \mathrm{C}$ instilled through the tracheal cannula by a syringe. After five gentle massages of the thorax, approximately $3 \times 0.7 \mathrm{ml}$ brochoalveolar lavage fluid (BAL) was retrieved from the lungs and collected in an ice-cold plastic tube. The cells were counted using a Sysmex KX-21 cell counter (TOA). Differential cell counts were performed on cytocentrifuge preparations (Labofuge A; Heraeus) and stained with May-Grunwald/Giemsa. Differential cell counts were determined from at least 500 cells, and calculated per ml BAL fluid. Serum OVA-specific IgE and IgG1 levels were determined in mouse sera by ELISA. For the determination of OVA-specific IgE, $100 \mu \mathrm{l}$ of rat anti mouse IgE heavy chain antibody (LO$\mathrm{ME}-3$, Serotec) at a concentration of $5 \mu \mathrm{g} / \mathrm{ml}$ bicarbonate buffer, $\mathrm{pH} 9.6$, were added to each well of ELISA microtiter plates (cert. Maxisorp, Nunc). The plates were incubated at $4^{\circ} \mathrm{C}$ for $3 \mathrm{hrs}$ then washed three times with wash buffer $+1 \%$ FCS. One hundred- $\mu$ l of OVA reference serum (100 relative units $/ \mathrm{ml}$ ) or test sera diluted in wash buffer $+1 \%$ FCS in threefold steps were distributed into each well and incubated for $2 \mathrm{hrs}$ at room temperature. Washing was repeated three times before $100 \mu$ of biotinylated OVA (1:6000) in wash buffer $+1 \%$ FCS were distributed into each well and incubated over night at $4^{\circ} \mathrm{C}$. After washing three times, 100 $\mu \mathrm{l}$ horseradish peroxidase avidin D (1:3000, Vector Labs) was added for $2 \mathrm{hrs}$ at room temperature. Plates were washed three times with wash buffer followed three times with substrate buffer before adding $100 \mu \mathrm{l}$ of the 
chromogen (5 mg orthophenyldiamine (Sigma)/10 ml phosphate citrate buffer containing $0.003 \% \mathrm{H}_{2} \mathrm{O}_{2}$ ) into each well and incubating them for fifteen minutes at room temperature. The reaction was stopped with $50 \mu \mathrm{l}$ $4 \mathrm{~N} \mathrm{H}_{2} \mathrm{SO}_{4}$ and the OD $492 \mathrm{~nm}$ read using a microtiter spectrophotometer (TECAN Spectra). The ODs of the serum samples were related to the standard curve and the amount of OVA-specific IgE were calculated. For determination of OVA-specific IgG1, $100 \mu \mathrm{l}$ of OVA at a concentration of $2 \mu \mathrm{g} / \mathrm{ml}$ bicarbonate buffer, $\mathrm{pH}$ 9.6, were added to each well of ELISA microtiter plates (cert. Maxisorp, Nunc). The plates were incubated at $37^{\circ}$ $\mathrm{C}$ for $2 \mathrm{hrs}$ and stored until use at $4^{\circ} \mathrm{C}$. Then the plates were washed three times with wash buffer. One hundred- $\mu$ l of OVA reference standard serum or test sera diluted in PBS + 1\% FCS in threefold steps were distributed into each well and incubated for $2 \mathrm{hrs}$ at $37^{\circ} \mathrm{C}$. Washing was repeated three times before $100 \mu \mathrm{l}$ of biotinylated anti-mouse IgG1 (The Binding Site, diluted $1: 10,000)$ were added to each well and incubated for 60 $\min$ at $37^{\circ} \mathrm{C}$. After repeated washings, $100 \mu \mathrm{l}$ of horseradish peroxidase (Vector Lab.) was added for $60 \mathrm{~min}$ at $37^{\circ} \mathrm{C}$, and then washed three times with wash buffer. The assay was developed using the same procedure as for OVA-specific IgE measurement. $\mathrm{PGE}_{2}$ in BALF was measured by ELISA (R\&D Systems) according to the manufacturer's instructions.

\section{Results}

Reduced IL-4 levels in Cerk ${ }^{-/-}$D011.10/RAG $1^{-/-}$mice challenged with ovalbumin

$T$ cell activation triggers signaling mechanisms that induce the production and secretion of cytokines. Functionally, cytokines have been classified as being either pro-inflammatory $\left(\mathrm{T}_{\mathrm{H}} 1\right.$ type) or anti-inflammatory $\left(\mathrm{T}_{\mathrm{H}} 2\right.$ type) depending on the final balance of their effects on the immune system. For analysis, we selected a panel of cytokines belonging to these two categories, namely IL2 , TNF- $\alpha$, INF- $\gamma\left(\mathrm{T}_{\mathrm{H}} 1\right)$ and IL-4, IL-13 and IL-5 $\left(\mathrm{T}_{\mathrm{H}} 2\right)$.

The four strains (wild-type (WT), Cerk ${ }^{-1-}, \operatorname{Sphk1}^{-/-}$and Sphk $2^{-1-}$ ), all in the DO11.10 RAG1 ${ }^{-1-}$ background, were challenged with ovalbumin. Blood samples were collected at $2 \mathrm{~h}$ and $4 \mathrm{~h}$ post challenge and the levels of the above-mentioned cytokines in the serum was measured using multiplex analysis (Fig. 1). IL-4 levels in the serum were reduced by $70 \%$ in Cerk $^{-1-}$ compared to WT $(\mathrm{p}=0.01)$ and compared to both SPHK-deficient animals. There was also a clear trend towards reduction of secreted IL-13 in Cerk $^{-1-}$ animals (- 45\%; $\mathrm{p}=0.10$ vs WT), which was observed neither with $S p h k 1^{-1-}$ nor

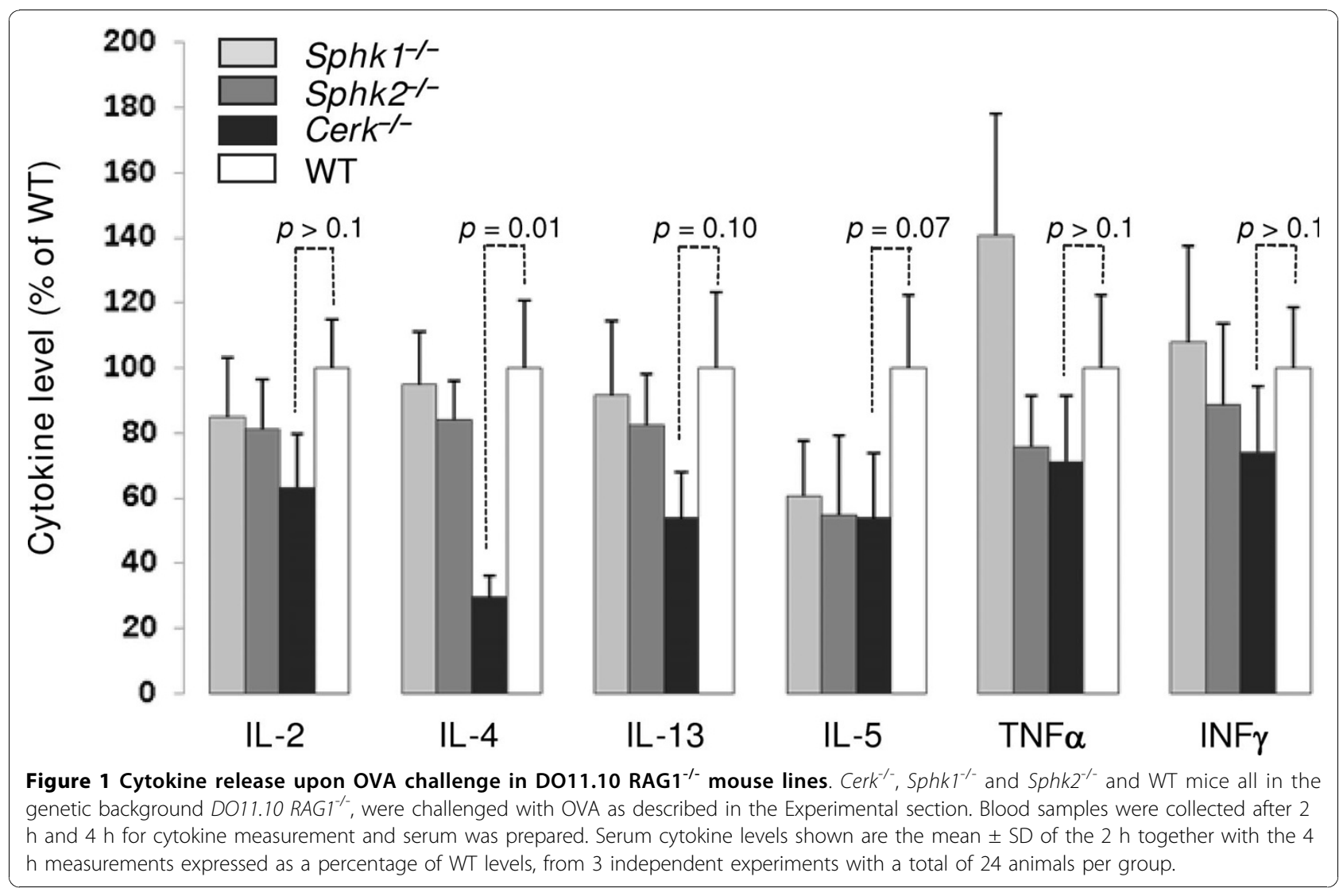




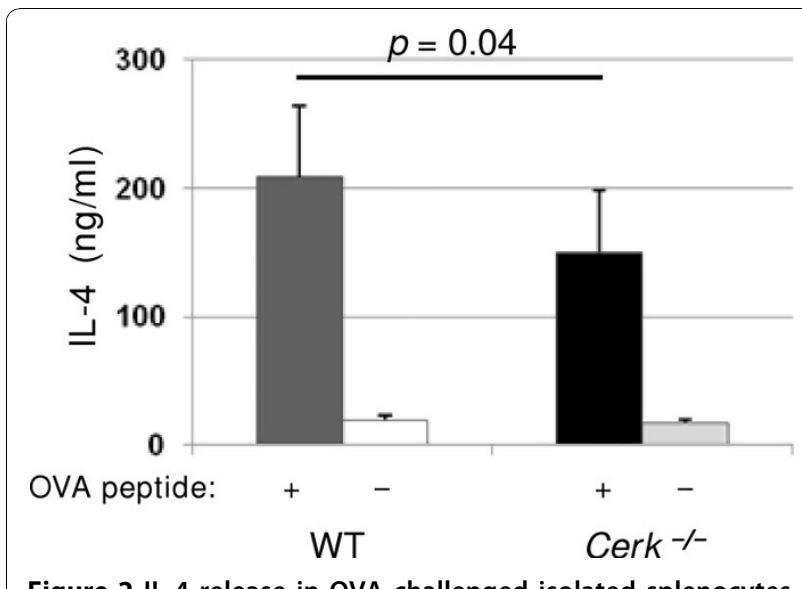

Figure 2 IL-4 release in OVA challenged isolated splenocytes Splenocytes from D011.10 RAG1 $1^{-1-}$ and from Cerk ${ }^{-1-}$ DO11.10 RAG1 ${ }^{-1-}$ mice were isolated following ovalbumin challenge in vivo as described in the Experimental section. Cultured splenocytes were then incubated with $10 \mu \mathrm{g} / \mathrm{ml} \mathrm{OVA}_{323-339}$ peptide or with saline (control) for 3.5 hours and IL-4 levels were measured in cell culture supernatant. The data shown represent the mean \pm SD of measurements obtained from 8 animals (OVA-treated) and 2 animals (controls). In this experiment it was not possible to match the age of the animal population optimally: DO11.10 RAG1 $1^{-1-}$ were 8 weeks of age at start of the experiment whereas Cerk ${ }^{-1-}$ D011.10 $R A G 1^{-1-}$ mice were between 11 and 14 weeks of age.

with $\operatorname{Sph} k 2^{-1-}$ animals. A trend for reduction of IL-5 levels (-45\%; $\mathrm{p}=0.07$ in Cerk $^{-1-}$ vs WT) was seen for all 3 knock-out strains. Levels for all other measured cytokines were not significantly different from WT levels.

To confirm the data obtained in vivo, we measured IL-4 secretion ex- vivo, from CERK-deficient DO11.10/ RAG $1^{-1-}$ splenocytes. After $3.5 \mathrm{~h}$ of ovalbumin peptide challenge in culture, the levels of IL-4 secreted by $\mathrm{Cerk}^{-1-}$ cells was reduced by $30 \%(\mathrm{p}=0.04)$ compared to WT cells (Fig. 2).

\section{$\mathrm{Cerk}^{-/-}$mice are not protected in an ovalbumin-induced} asthma model

IL-4, IL-5 and IL-13 are key cytokines for adaptive immunity, produced by $\mathrm{CD} 4^{+} \mathrm{T}$ cells of the $\mathrm{T}_{\mathrm{H}} 2$ type. The overall reduced production of these cytokines in Cerk $^{-1-}$ DO11.10/RAG1 ${ }^{-1-}$ mice therefore suggested a possible contribution of CERK to $\mathrm{T}_{\mathrm{H}} 2$ cell biology. In addition, because IL-4 and IL-13 are important regulators of immediate hypersensitivity reactions by inducing B cell immunoglobulin (Ig) heavy chain class switching to the IgE isotype, the strong depletion of IL-4 levels in absence of CERK might have broader implications. Therefore, we submitted Cerk $^{-1-}$ mice to an ovalbumin-induced asthma model, where cytokines such as IL-4 and IL-13 are playing key roles. We measured leukocyte infiltration, immunoglobulin levels in the serum as well as inflammatory mediator release. When assessed 2 days after the final ovalbumin aerosol challenge, the numbers of eosinophils, macrophages, lymphocytes and neutrophils, harvested from the bronchoalveolar lavage fluid, were indistinguishable in WT and Cerk $^{-1-}$ animals (Fig. 3A). Similar observations were made for IgG1 and IgE levels (Fig. 3B) and for prostaglandin (PG) $\mathrm{E}_{2}$ levels (Fig. $3 \mathrm{C}$ ).

\section{Discussion}

The results obtained with $\mathrm{Cerk}^{-1-}$ compared to Sphk1/and $S p h k 2^{-1-}$, in the DO11.10/RAG1 ${ }^{-1-}$ genetic background, revealed that IL-4 production and/or release, after T-cell activation, is dependent on CERK (Fig. 1 and Fig. 2). Furthermore, even if this did not reach statistical significance, the same experiments also revealed that IL13 and IL-5 levels are reduced in absence of CERK (Fig. 1). Altogether, this suggested that CERK may play a role in $\mathrm{T}_{\mathrm{H}} 2$ cytokine production. Remarkably however, $\mathrm{Cerk}^{-1-}$ animals (in the normal Balb/C background) were not protected in an asthma model where $\mathrm{T}_{\mathrm{H}} 2$ cells are considered to be a driving force (Fig. 3). It is possible that reduction of IL-4 levels in absence of CERK has not been sufficient to limit the immune response; equally possible might be the mechanistic redundancy between cytokines (e.g. IL-4 and IL-13; levels of the latter are only partially reduced in absence of CERK; Fig. 1). An alternative explanation might be differential compensation in a background of $\mathrm{C} 1 \mathrm{P}$ reduction (due to absence of CERK) in the two models. Readouts in DO11.10 were taken after 2 to $4 \mathrm{~h}$ whereas analysis in the asthma model took place after $48 \mathrm{~h}$; compensatory C1P synthesis (by unknown mechanisms, cf ref. [2]) might be limiting only for short period of times. Altogether, despite a clear cut influence on IL-4 levels, to what extent CERK may participate in $\mathrm{T}_{\mathrm{H}} 2$ cell biology remains elusive. Interestingly, however, infectious reagents such as LPS or the $\mathrm{T}_{\mathrm{H}} 1$ cytokine INF- $\gamma$ can inhibit CERK at mRNA levels in primary macrophages (P. Rovina and F. Bornancin, unpublished data) thus supporting the notion that CERK activity may be positively linked to the $T_{H} 2$ rather than to the $T_{H} 1$ phenotype (Fig. 4).

Basal levels of $\mathrm{PGE}_{2}$ in BAL fluid were significantly reduced in control $\mathrm{Cerk}^{-1-}$ compared to control WT mice (Fig. 3C). In fact, this observation provides first in vivo support to the hypothesis that CERK signals to cPLA2, which has already been well validated in vitro [6-9]. It also indicates that the contribution of CERK/ C1P to cPLA2 function might be best evidenced when cPLA2 is sub-optimally activated. Other mechanisms may prevail under developing acute or chronic inflammation e.g. during the asthma model presented here.

In addition to the asthma model of the present work, other disease models of the lung were tested with $\mathrm{Cerk}^{-1-}$ mice. A smoke-induced chronic obstruction model, where increased sensitivity in the absence of 

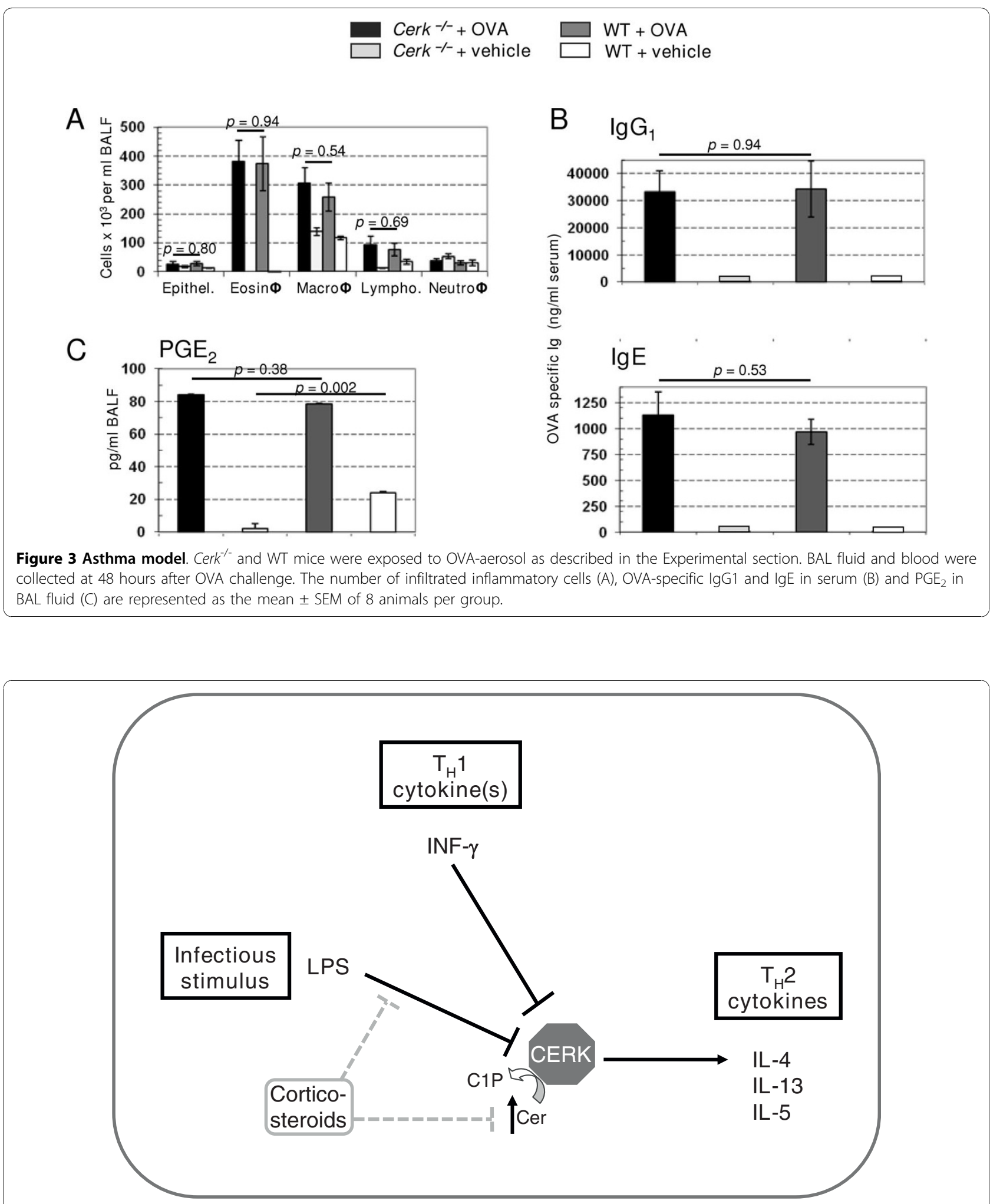

Figure 4 CERK and $T_{H} 1 / T_{H} 2$ cytokines. This schematic representation summarizes the current knowledge of the interplay between CERK and cytokines. The $T_{H} 1$ cytokine INF- $\gamma$ as well as LPS can repress CERK at transcriptional level in primary mouse macrophages which indicates that a $T_{H} 1$ response may require initial down-regulation of CERK; this can be reversed by corticosteroids. The present work provides evidence that $T_{H} 2$ cytokine production, IL-4 in particular, are dependent on CERK. Altogether, this suggests that CERK may polarize immune responses towards the $\mathrm{T}_{\mathrm{H}} 2$ type. 
CERK may be expected because of up-regulated ceramide levels [3], failed to reveal significant differences between $\mathrm{Cerk}^{-1-}$ and WT control littermates (data not shown). A bleomycin-induced fibrosis model, where IL13 is key, also did not show differences between $\mathrm{Cerk}^{-1-}$ and WT control littermates (data not shown). In fact, the sole lung pathology where we observed a statistically different behavior in $\mathrm{Cerk}^{-1-}$ compared with WT is an infection model with S. pneumoniae, as already reported [3]. During this fulminant infection, absence of CERK led to drastic worsening of the disease resulting in early mortality. We initially speculated on increased ceramide levels in absence of CERK leading to premature neutrophil apoptosis and inefficient first line defense [3]. Should the $\mathrm{T}$ cells be polarized by CERK towards the $\mathrm{T}_{\mathrm{H}} 2$ type (Fig. 4), the opposite hypothesis could also be considered, i.e. hyperactivation of host defenses in $\mathrm{Cerk}^{-1-}$ mice might have led to poor control of the infection. In fact, the dynamic (as opposed to "established" i. e. in KO animals) down-regulation of CERK might represent a negative feedback mechanism. Clearly, further experiments are required to understand the contribution of CERK to inflammation. In light of available data including the results of the present study, CERK may play a 'fine tuning' role in inflammatory processes.

\section{Abbreviations}

BAL: (bronchoalveolar); CERK: (ceramide kinase); C1P: (ceramide-1-phosphate); ELISA: (enzyme linked immunosorbent assay); Ig: (immunoglobulin); IL: (interleukin); INF: (interferon); OVA: (ovalbumin); SPHK: (sphingosine kinase); $\left(T_{H}\right)$ : T Helper; WT: (wild-type).

\section{Acknowledgements}

We would like to thank Dr. Barbara Zemann for contributing to the early phase of this project as well as Christine Graf, Raphaela Kutil, and Claudia Reichel for expert technical assistance.

\section{Author details}

Novartis Institutes for BioMedical Research, Brunnerstrasse 59, A-1235

Vienna, Austria. ${ }^{2}$ Current address: German Heart Centre Munich, Lazarettstrasse 36, D-80636 München, Germany.

\section{Authors' contributions}

$\mathrm{SN}, \mathrm{NU}, \mathrm{TB}, \mathrm{AB}$ and FB conceived and designed the experiments; SN and NU performed the experiments, $S N, A B$ and FB performed the statistical analyses; FB wrote the manuscript. All authors read and approved the final manuscript.

\section{Competing interests}

All authors are present ( $\mathrm{SN}, \mathrm{TB}, \mathrm{AB}, \mathrm{FB})$ or former (NU) employees of Novartis

\section{Received: 5 November 2009}

Accepted: 6 January 2010 Published: 6 January 2010

\section{References}

1. Sugiura M, Kono K, Liu H, Shimizugawa T, Minekura H, Spiegel S, Kohama T: Ceramide kinase, a novel lipid kinase: Molecular cloning and functional characterization. Journal of Biological Chemistry 2002, 277(26):23294-300.

2. Boath A, Graf C, Lidome E, Ullrich T, Nussbaumer P, Bornancin F: Regulation and traffic of ceramide 1-phosphate produced by ceramide kinase: Comparative analysis to glucosylceramide and sphingomyelin. Journal of Biological Chemistry 2008, 283(13):8517-26.
3. Graf C, Zemann B, Rovina P, Urtz N, Schanzer A, Reuschel R, Mechtcheriakova D, Muller M, Fischer E, Reichel C, Huber S, Dawson J, Meingassner JG, Billich A, Niwa S, Badegruber R, Van Veldhoven PP, Kinzel B , Baumruker T, Bornancin F: Neutropenia with impaired immune response to Streptococcus pneumoniae in ceramide kinase-deficient mice. Journal of Immunology 2008, 180(5):3457-66.

4. Gomez-Munoz A, Duffy PA, Martin A, O'Brien L, Byun H-S, Bittman R: Shortchain ceramide-1-phosphates are novel stimulators of DNA synthesis and cell division: Antagonism by cell-permeable ceramides. Molecular Pharmacology 1995, 47(5):883-9.

5. Gomez-Munoz A: Ceramide 1-phosphate/ceramide, a switch between life and death. Biochimica et Biophysica Acta-Biomembranes 2006, 1758(12):2049-56.

6. Lamour NF, Subramanian P, Wijesinghe DS, Stahelin RV, Bonventre JV, Chalfant CE: Ceramide 1-Phosphate Is Required for the Translocation of Group IVA Cytosolic Phospholipase A2 and Prostaglandin Synthesis. Journal of Biological Chemistry 2009, 284(39):26897-907.

7. Pettus BJ, Bielawska A, Spiegel S, Roddy P, Hannun YA, Chalfant CE: Ceramide kinase mediates cytokine- and calcium ionophore-induced arachidonic acid release. Journal of Biological Chemistry 2003, 278(40):38206-13.

8. Pettus BJ, Bielawska A, Subramanian P, Wijesinghe DS, Maceyka M, Leslie CC , Evans JH, Freiberg J, Roddy P, Hannun YA, Chalfant CE: Ceramide 1Phosphate Is a Direct Activator of Cytosolic Phospholipase A2. Journal of Biological Chemistry 2004, 279(12):11320-6.

9. Subramanian P, Vora M, Gentile LB, Stahelin RV, Chalfant CE: Anionic lipids activate group IVA cytosolic phospholipase $A[2]$ via distinct and separate mechanisms. Journal of Lipid Research 2007, 48(12):2701-2708.

10. Graf C, Klumpp M, Habig M, Rovina P, Billich A, Baumruker T, Oberhauser B, Bornancin F: Targeting ceramide metabolism with a potent and specific ceramide kinase inhibitor. Molecular Pharmacology 2008, 74(4):925-32.

11. Mitsutake S, Yokose U, Kato M, Matsuoka I, Yoo J-M, Kim T-J, Yoo H-S, Ando $Y$, Sugiura $M$, Kohama $T$, Igarashi $Y$ : The generation and behavioral analysis of ceramide kinase-null mice, indicating a function in cerebellar Purkinje cells. Biochemical and Biophysical Research Communications 2007, 363(3):519-24.

12. Niwa S, Graf C, Bornancin F: Ceramide kinase deficiency impairs microendothelial cell angiogenesis in vitro. Microvascular Research 2009, 77(3):389-93

13. Dressler KA, Kolesnick RN: Ceramide 1-phosphate, a novel phospholipid in human leukemia (HL-60) cells. Synthesis via ceramide from sphingomyelin. Journal of Biological Chemistry 1990, 265(25):14917-21.

14. Kolesnick RN, Hemer MR: Characterization of a ceramide kinase activity from human leukemia (HL-60) cells. Separation from diacylglycerol kinase activity. Journal of Biological Chemistry 1990, 265(31):18803-8.

15. Yanaga F, Watson SP: Ceramide does not mediate the effect of tumour necrosis factor alpha on superoxide generation in human neutrophils. Biochemical Journal 1994, 298(3):733-8.

16. Hinkovska-Galcheva VT, Boxer LA, Mansfield PJ, Harsh D, Blackwood A, Shayman JA: The formation of ceramide-1-phosphate during neutrophil phagocytosis and its role in liposome fusion. Journal of Biological Chemistry 1998, 273(50):33203-33209.

17. Mitsutake S, Kim T-J, Inagaki Y, Kato M, Yamashita T, Igarashi Y: Ceramide Kinase Is a Mediator of Calcium-dependent Degranulation in Mast Cells. Journal of Biological Chemistry 2004, 279(17):17570-7.

18. Murphy MKenneth, Heimberger BAmy, Dennis Loh: Induction by antigen of intrathymic apoptosis of CD4+CD8+ TCRlo thymocytes in vivo. Science 1990, 250:1720-1723.

19. Lee WT, Cole-Calkins J, Street NE: Memory T cell development in the absence of specific antigen priming. J Immunol 1996, 157(12):5300-7.

20. Hayashi RJ, Loh DY, Kanagawa O, Wang F: Differences Between Responses of Naive and Activated T Cells to Anergy Induction. J Immunol 1998, 160(1):33-8.

21. Zemann B, Kinzel B, Muller M, Reuschel R, Mechtcheriakova D, Urtz N, Bornancin F, Baumruker T, Billich A: Sphingosine kinase type 2 is essential for lymphopenia induced by the immunomodulatory drug FTY720. Blood 2006, 107(4):1454-8.

doi:10.1186/1476-511X-9-1

Cite this article as: Niwa et al:: Ovalbumin-induced plasma interleukin-4 levels are reduced in ceramide kinase-deficient D011.10 RAG1 ${ }^{-1-}$ mice. Lipids in Health and Disease 2010 9:1. 